\title{
Claudin- 4 controls the proliferation, apoptosis, migration and in vivo growth of MCF-7 breast cancer cells
}

\author{
XIAOTANG MA ${ }^{1}$, HUILAI MIAO ${ }^{2}$, BAOGUO JING $^{3}$, QUNWEN PAN $^{1}$, HUITING ZHANG $^{1}$, \\ YANFANG CHEN $^{1}$, DAN ZHANG $^{3}$, ZHONGZENG LIANG $^{2}$, ZHILI WEN $^{4}$ and MINGYI LI ${ }^{2}$ \\ ${ }^{1}$ Clinical Research Center, ${ }^{2}$ Department of Surgery; ${ }^{3}$ Cancer Center, Affiliated Hospital of Guangdong \\ Medical College, Zhanjiang, Guangdong 524001; ${ }^{4}$ Affiliated Hospital of Infectious Diseases, \\ Nanchang University, Nanchang, Jiangxi 330002, P.R. China
}

Received January 14, 2015; Accepted April 20, 2015

DOI: $10.3892 / o r .2015 .4037$

\begin{abstract}
Previous studies have shown that the expression of claudin-4 is upregulated in breast cancer. The aim of the present study was to investigate the role and the regulation of claudin-4 in MCF-7 breast cancer cells. For the in vitro experiments, MCF-7 cells were treated with recombinant vectors carrying cDNA for claudin-4 overexpression or short hairpin RNAs (shRNAs) for claudin-4 silencing. Cell proliferation was determined by an MTT assay and cell migration ability was measured by a wound-healing assay. The cell cycle profile and apoptotic rate were analyzed using flow cytometry. The effect of methylation status on claudin-4 expression was determined by PCR and western blotting. For the in vivo tumorigenesis analysis, MCF-7 cells with or without claudin- 4 silencing were transplanted into nude mice. In vivo cell growth was evaluated 14 days after transplantation. We found that claudin- 4 overexpression increased MCF-7 cell proliferation and migration, and reduced the rate of cell apoptosis. Silencing of claudin-4 induced the opposite effects in MCF-7 cells. In addition, claudin-4 expression was upregulated by demethylation. Moreover, the size of tumor formation was reduced in nude mice transplanted with claudin- 4 silenced MCF-7 cells. These observations suggested that claudin-4, which was regulated by methylation status, plays an important role in breast cancer growth and malignancy via the control of cell proliferation, migration and apoptosis.
\end{abstract}

Correspondence to: Professor Mingyi Li, Department of Surgery, Affiliated Hospital of Guangdong Medical College, 57 South Renmin Road, Zhanjiang, Guangdong 524001, P.R. China

E-mail: limingyi63@163.com

Professor Zhili Wen, Affiliated Hospital of Infectious Diseases, Nanchang University, 167 Middle Hongdu Street, Nanchang, Jiangxi 330002, P.R. China

E-mail: wenzhili@126.com

Key words: claudin-4, breast cancer, MCF-7 cell function, tumorigenesis, methylation

\section{Introduction}

Breast cancer is a common cancer and the second leading cause of cancer-related mortality in women. The limits in identifying patient subsets and the complexity of the disease presentation lead to major difficulties in current breast cancer diagnostic and therapeutic strategies (1). Investigations aiming to identify the genes responsible for promoting the growth and malignancy of breast cancer may provide insight into the nature of this disease.

The claudin family includes 24 related members which are integral transmembrane proteins (2). These members are the major components of the tight junction and are important in various cell activities through interaction with a variety of proteins in signaling pathways $(3,4)$. The claudins are often tissue-specifically expressed $(5,6)$, and a number of studies have described the abnormal expression of claudins in various types of cancer, such as breast cancer, hepatocellular carcinoma, colonic cancer, lung squamous cell and bladder carcinoma (7-14). Moreover, claudins are considered to participate in the pathology of these disorders (9-14). For example, claudin-5 has been reported to be downregulated and correlated with poor prognosis in patients with hepatocellular carcinoma (9). Additionally, claudin-1 is reduced in stage II colonic cancer and may be associated with recurrence and poor patient survival (14). These results suggest that the claudin family members are pivotal in tumorigenesis and cancer progression.

The relationship of TJs dysfunction with disease development in breast cancer has been shown. Claudin-1 has been suggested to function as a tumor suppressor and a tumor enhancer/facilitator in breast cancer $(1,15,16)$. Osanai et al $(17)$ found that claudin- 6 knockout enhanced the migration and invasion of the human MCF-7 breast cancer cells. As an important member of the claudin family, claudin- 4 has been investigated in breast cancer $(7,8)$. In a case-controlled study of breast cancer, claudin-4 was found to be overexpressed and associated with high tumor grade and poor prognosis of the disease (18). Moreover, claudin-4 positivity has been associated with a shorter disease-free survival of patients with luminal breast cancer $(19,20)$. Collectively, the abovementioned studies indicate that claudin- 4 is a potential molecular marker for 
breast cancer. However, the functional role and regulation of claudin-4 in breast cancer remains unknown.

In the present study, we aimed to investigate the biological function and regulation of claudin- 4 in breast cancer cells in in vitro and in vivo experiments.

\section{Materials and methods}

Cells and animals. The human MCF-7 breast cancer cells were obtained from the Shanghai Bioleaf Biotech Co., Ltd. The cells were grown in RPMI-1640 medium (Gibco, Grand Island, NY, USA) supplemented with $10 \%$ fetal bovine serum (FBS; Gibco) and antibiotics at $37^{\circ} \mathrm{C}$ in the presence of $95 \%$ air and $5 \% \mathrm{CO}_{2}$. Female BALB/c nude mice (4-6 weeks old) were purchased from the Experiment Animal Center of Guangdong, and maintained in a pathogen-free facility.

Vector constructs. The 659-bp claudin-4 cDNA was amplified by PCR and cloned into the EcoRI/BamHI sites of the green fluorescence protein expression vector pEGFP-C1 [Beijing Genomics Institute (BGI), Beijing, China], resulting in the claudin-4-expressing construct pEGFP-C1-Cldn4. Short hairpin RNAs (shRNAs) targeting the open reading frame of human claudin-4 was cloned into the XhoI/HpaI sites of the green fluorescence protein expressing vector PLL3.7 (BGI) to generate the PLL3.7-siCldn4 vector. shRNA was purchased from BGI and the primer sequences used were: Claudin-4 shRNA sense, TGTGTACCAACTGCCTGGAGGATGA ATTCAAGAGATTCATCCTCCAGGCAGTTGGTACAC TTTTTTC and antisense, TCGAGAAAAAAGTGTACCA ACTGCCTGGAGGATGAATCTCTTGAATTCATCCTCC AGGCAGTTGGTACACA. Scrambled shRNAs were used to generate the PLL3.7-scramble control vector. The sequences used were: Scrambled shRNA sense, TGCCCTAGTGTAGAT GGCTGCAAGAATTCAAGAGATTCTTGCAGCCATCTA CACTAGGGCTTTTTTC and antisense, TCGAGAAAA AAGCCCTAGTGTAGATGGCTGCAAGAATCTCTTG AATTCTTGCAGC CATCTACACTAGGGCA.

Generation of stable cell lines with claudin-4 overexpression or knockdown. Cells were cultured to $80 \%$ confluency and transfection was carried out using Lipofectamine 2000 (Invitrogen, Carlsbad, CA, USA) following the manufacturer's instructions. To generate the claudin-4-overexpressing MCF-7 cell clones, the claudin-4-expressing vector pEGFP-C1-Cldn4 was transfected. The cell clones with stable claudin- 4 overexpression were selected in $150 \mu \mathrm{g} / \mathrm{ml} \mathrm{G} 418$ (MDBio, Qingdao, China) medium and were used for proliferation, migration and apoptosis assays. MCF-7 cells transfected with pEGFP-C1 empty vector were considered the control.

For claudin- 4 knockdown, the MCF-7 cells were transfected with PLL3.7-siCldn4 or control vectors (PLL3.7-scramble) using Lipofectamine 2000 following the manufacturer's instructions. The cell clones with stable knockdown of claudin-4 were selected in G418 $(150 \mu \mathrm{g} / \mathrm{ml})$ medium and were used for the in vitro proliferation, migration and apoptosis assays, as well as in vivo nude mouse experiment.

$R T-P C R$. Total RNA was isolated from the cell lines using a TRIzol reagent kit (Invitrogen) according to the manufacturer's instructions. RNA samples were then reverse transcribed into cDNA using an MML-V reverse transcription kit (Invitrogen) in a total volume of $20 \mu \mathrm{l}$ according to the manufacturer's instructions. Equal amounts of cDNA samples were used for RT-PCR to detect the level of claudin-4 expression under the following conditions: $3 \mathrm{~min}$ at $95^{\circ} \mathrm{C}$, followed by a total of 40 cycles of two temperature cycles $\left(15 \mathrm{sec}\right.$ at $90^{\circ} \mathrm{C}$ and $1 \mathrm{~min}$ at $60^{\circ} \mathrm{C}$ ). The primers and annealing temperatures used for PCR are shown in Table I. GAPDH was used as an internal control (housekeeping gene). The relative quantification of claudin-4 was determined using the comparative CT method $\left(2^{-\Delta \Delta C t}\right)$.

Western blotting. For the western blot analysis, $30 \mu \mathrm{g}$ protein lysates from the cells were separated by $10 \%$ SDS-PAGE on Tris-glycine gels (Invitrogen) and transferred to polyvinylidene difluoride membranes (Millipore Corporation, Bedford, MA, USA). The membranes were blocked for $1 \mathrm{~h}$ at room temperature in TBS (50 mM Tris, $150 \mathrm{mM} \mathrm{NaCl}, \mathrm{pH} 7.6,5 \%$ fat-free dry milk) and washed in $0.5 \%$ Tween-20 in TBS (TBST), and $2 \mathrm{~min}$ at room temperature. Rabbit anti-claudin- 4 antibody (1:750; Invitrogen) was added for and the cells were incubated overnight at $4^{\circ} \mathrm{C}$ and then washed in TBST. $\beta$-actin $(1: 1,000$; EarthOx, San Francisco, CA, USA) was used to normalize protein loading. A secondary antibody (1:100,000; EarthOx) was added for $1 \mathrm{~h}$ at room temperature. The membranes were washed in TBST and signal detection was carried out using ECL solution (Amersham, Sweden).

Cell proliferation assay. The proliferative capabilities of cells with claudin-4 knockdown/overexpression and corresponding controls were measured using a 3-[4,5-dimethylthiazyol-2yl]2,5-diphenyltetrazolium bromide (MTT) assay $(5 \mathrm{mg} / \mathrm{ml}$; Sigma, St. Louis, MO, USA). Cells were seeded in 96-well plates at a concentration of $2 \times 10^{3}$ cells/well containing $200 \mu 1$ of RPMI-1640 cell culture medium supplemented with $10 \%$ FBS. Every $24 \mathrm{~h}$ of culture in 5 days, $20 \mu \mathrm{l}$ of MTT solution was added and cells were incubated for $4 \mathrm{~h}$ at $37^{\circ} \mathrm{C}$. Then $150 \mu \mathrm{l}$ DMSO was added to each well, and the cells were incubated for $20 \mathrm{~min}$ at $37^{\circ} \mathrm{C}$. The optical density (OD) value of cells was read at $490 \mathrm{~nm}$ in a microplate reader (BioTek, Winooski, VT, USA). Cells in triplicate wells were counted at each time point, and the experiment was repeated in three independent experiments.

Cell cycle profile. Cell cycle profiles were analyzed using flow cytometry after the propidium iodide labeling of DNA, as previously described $(21,22)$.

Cell migration assay. The migration rate of breast cancer cells was measured by a wound-healing assay. The cells were grown to confluence on $60-\mathrm{mm}$ cell culture dishes. A scratch was made through the cell monolayer using a pipette tip. After washing with phosphate-buffered saline (PBS), $0.5 \%$ FBS maintenance medium was added. Images of the wounded area were captured immediately after making the scratch ( $0 \mathrm{~h}$ time-point) and the invasion of cells into the wounded area was monitored once every $8 \mathrm{~h}$ for $48 \mathrm{~h}$ using an inverted microscope (LEICA DFC500, Germany).

Apoptosis assay. MCF-7 cells with claudin-4 overexpression or knockdown and the corresponding controls were 
Table I. Primer sequences and annealing temperature for real-time PCR.

Annealing temperature

Primer

Primer sequence

$\left({ }^{\circ} \mathrm{C}\right)$

Claudin-4

$\mathrm{F}$

R

GAPDH

$\mathrm{F}$

R

MS-PCR

Methylated
M-F
M-R

Unmethylated

$\mathrm{U}-\mathrm{F}$

U-R
5'-TTCATCGGCAGCAACATTGTCACC-3' 5'-AGTCGTACACCTTGCACTGCATCT-3'

5'-GAAGGTGAAGGTCGGAGTC-3'

5'-CAGAGTCCGTGAAGGCAG-3'
60

57

5'-CTACCGATAAAAACCGTCACG-3'

5'-GTGTATTTTGCGAACGTTAAGTTC-3'

5'-AATATTACTACCAATAAAAACCATCACAC-3'

5'-TGTATTTTGTGAATGTTAAGTTTGT-3'

F, forward; R, reverse.

seeded into $60-\mathrm{mm}$ cell culture dishes at a concentration of $4 \times 10^{5}$ cells/well. To induce apoptosis, the cells were treated with $0.1 \mu \mathrm{g} / \mathrm{ml}$ chemotherapeutic drug 5-fluoro-2,4 (1 and $3 \mathrm{H}$ ) pyrimidinedione (5-FU) (Sigma) for $24 \mathrm{~h}$. Apoptotic cells were detected by the PE Annexin V apoptosis detection kit (BD Biosciences, San Diego, CA, USA). The cells were labeled with Annexin V-PE and 7-AAD following the manufacturer's instructions. The percentage of Annexin V-labeled cells was measured by flow cytometric analysis using FACSCalibur flow cytometry (BD Biosciences).

Methylation-specific PCR. The methylation status was detected using methylation-specific PCR (MSPCR) as previously described (23). The primers and annealing temperatures used for MSPCR are shown in Table I. Genomic DNA was extracted and purified from the cell lines using a QIAamp DNA Mini kit (Qiagen, Germany) according to the manufacturer's instructions. Bisulfite modification was performed according to the manufacturer's instructions of the EpiTect ${ }^{\circledR}$ Plus DNA Bisulfite kit (Qiagen). The PCR mixture contained 10X Maxima Hot Start Taq buffer, $5 \mathrm{mmol} / 1 \mathrm{MgCl}_{2}, 2 \mu \mathrm{ldNTP}$ $10 \mathrm{mmol} / \mathrm{l}, 0.125 \mu \mathrm{l}$ Maxima Hot Start Taq DNA Polymerase (all reagents from Thermo Scientific, UK), $1 \mu 1$ each of forward and reverse primers, and $2 \mu 1$ of DNA brought to a total volume of $25 \mu \mathrm{l}$ by the addition of autoclaved deionized water. PCR reactions were hot started at $95^{\circ} \mathrm{C}$ for $5 \mathrm{~min}$, followed by 35 cycles $\left(30 \mathrm{sec}\right.$ at $95^{\circ} \mathrm{C}, 30 \mathrm{sec}$ at the annealing temperature, $30 \mathrm{sec}$ at $72^{\circ} \mathrm{C}$ ) and a final $7-\mathrm{min}$ elongation at $72^{\circ} \mathrm{C}$. Each PCR product was loaded into a $1 \%$ agarose gel, stained with ethidium bromide and visualized under UV illumination.

To assess the effect of DNA methylation, the cell lines were treated with $10 \mu \mathrm{mol} / 1$ 5-AZA-2V-deoxycytidine (5-AZA; Sigma), an inhibitor of DNA methylation. Treatment of cell cultures started at $30-40 \%$ confluence for a total of 3 days. The medium and drug were changed every $24 \mathrm{~h}$. RT-qPCR and western blotting were then performed to detect the level of claudin- 4 .

In vivo tumor growth. Animal experiments were carried out according to the protocol approved by the Animal Studies Committee at Guangdong Medical College. Six-week-old female BALB/c nude mice were housed in sterile microisolators, and were randomly divided into two groups $(n=6)$ each for subcutaneous injection of $2 \times 10^{6} / 100 \mu \mathrm{l}$ MCF-7 cells with claudin-4 knockdown or control MCF-7 cells into the breast fat. After 14 days, the mice were sacrificed for tumor dissection. The length and width were measured with metric calipers for tumor volume calculation using the equation: Volume $=\mathrm{le}$ ngth $\mathrm{x}$ width $\mathrm{x}$ width/2.

Statistical analysis. Data are presented as the mean \pm SD. Comparisons for two groups were performed using a Student's t-test (GraphPad Prism 5 software). Multiple comparisons were performed by one- or two-way ANOVA. $\mathrm{P}<0.05$ was considered to indicate a statistically significant result.

\section{Results}

Overexpression of claudin-4 in MCF-7 cells. The MCF-7 cells with pEGFP-C1 and pEGFP-C1-Cldn4 stable transfection were observed by fluorescence microscope (Fig. 1A). In MCF-7 cells treated with vector pEGFP-C1-Cldn4 (claudin-4 overexpression), claudin-4 expression increased (7.34 \pm 1.38 )-fold at the mRNA level and $(2.41 \pm 0.69)$-fold at the protein level in comparison to the pEGFP-C1-transfected cells (control) $(\mathrm{P}<0.01$, Fig. 1B and $\mathrm{C})$.

Knockdown of claudin-4 in MCF-7 cells. The green fluorescence of the PLL3.7-scramble and PLL3.7-siCldn4 stably transfected MCF-7 cells were observed using 
A
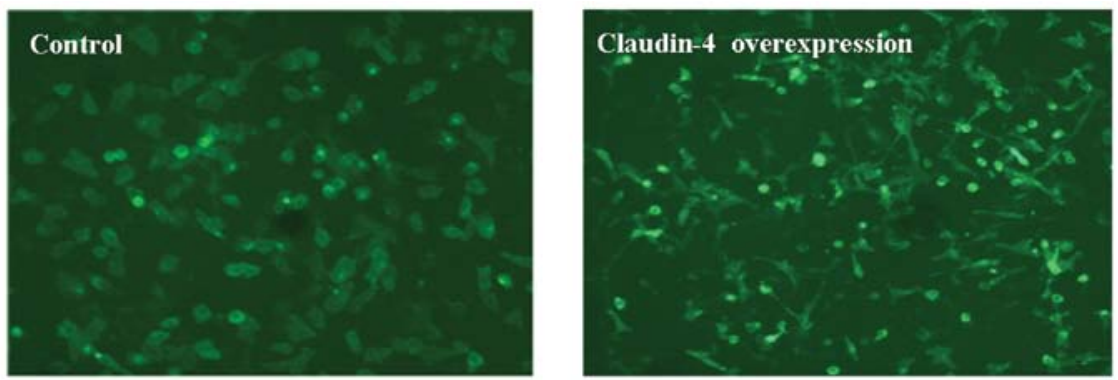

B

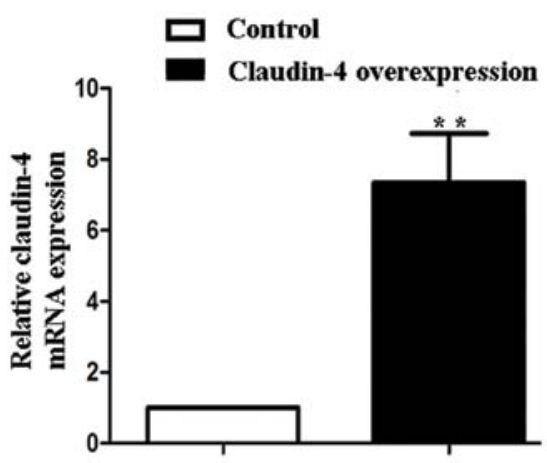

C

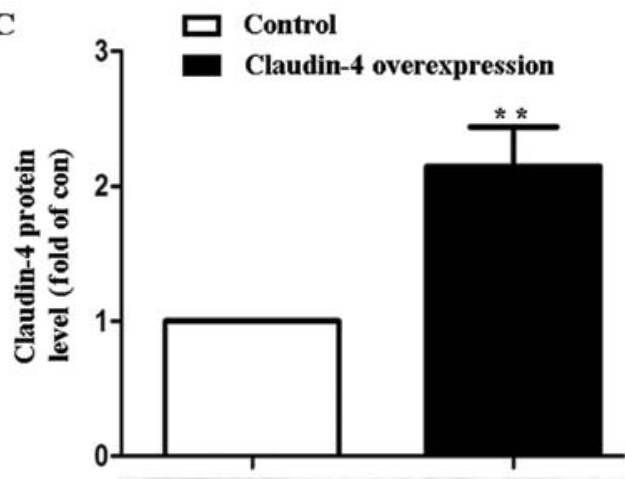

Claudin-4

Actin

Figure 1. Overexpression of claudin-4 in MCF-7 cells. (A) Claudin-4 overexpression and control cells were observed by fluorescence microscope. (B and C) RT-PCR and western blot analysis of claudin-4 expression in claudin-4 overexpressed MCF-7 cells compared to the control cells. Claudin-4 overexpression, pEGFP-C1-Cldn4 stably transfected MCF-7 cells; control, pEGFP-C1 stably transfected cells. The results are presented as the mean \pm SD $(\mathrm{n}=3) .{ }^{* *} \mathrm{P}<0.01$ vs. control.
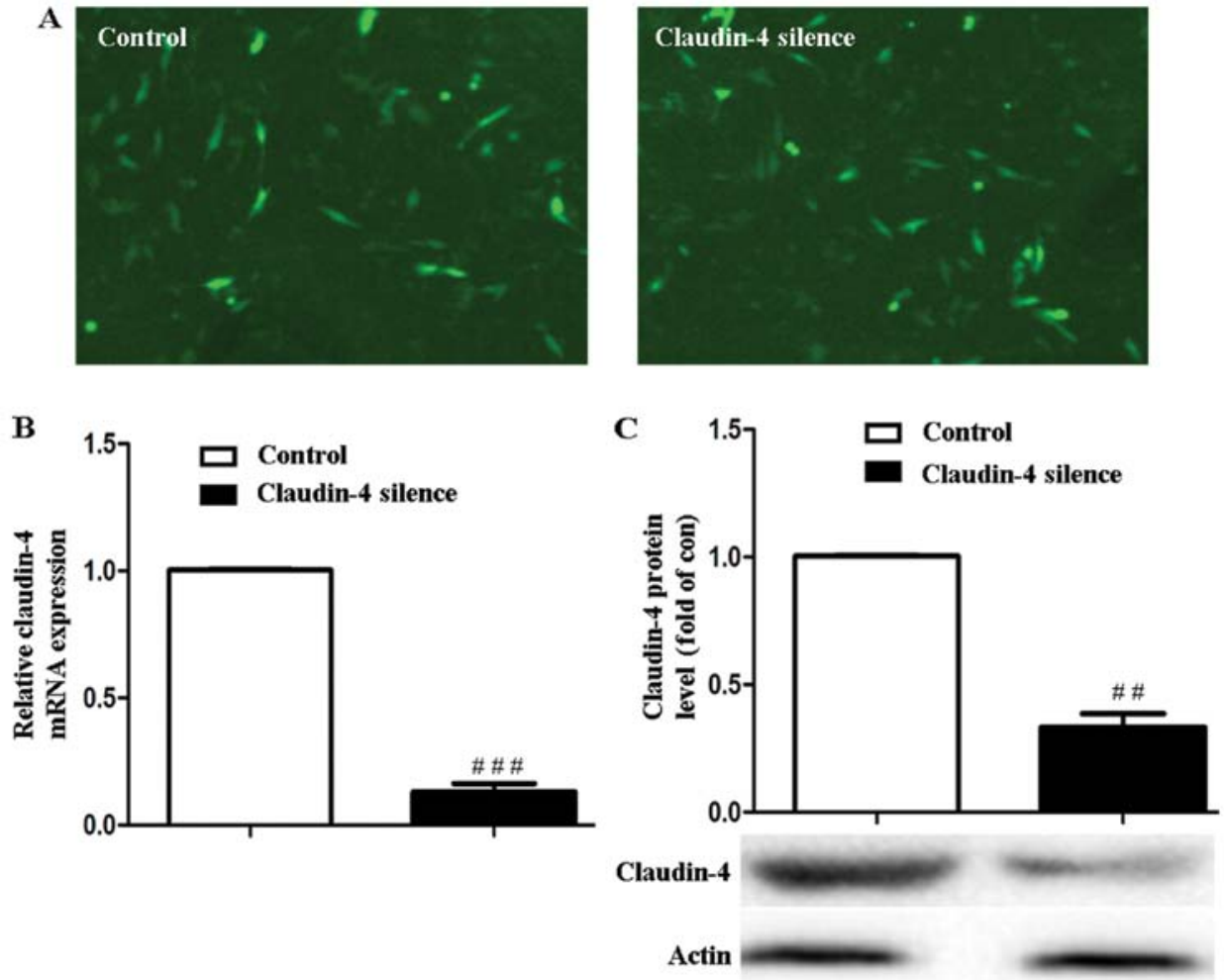

Figure 2. Knockdown of claudin-4 in MCF-7 cells. (A) Claudin-4 silencing and control cells were observed by fluorescence microscope. (B and C) RT-PCR and western blot analysis of claudin-4 expression in claudin-4-silenced cells compared to the control cells. Claudin-4 silencing, PLL3.7-siCldn4 stably transfected MCF-7 cells; control, PLL3.7-scramble stably transfected MCF-7 cells. The results are presented as the mean $\pm \mathrm{SD}(\mathrm{n}=3)$. ${ }^{\# \#} \mathrm{P}<0.01$ and ${ }^{\# \# \#} \mathrm{P}<0.001 \mathrm{vs}$. control. 

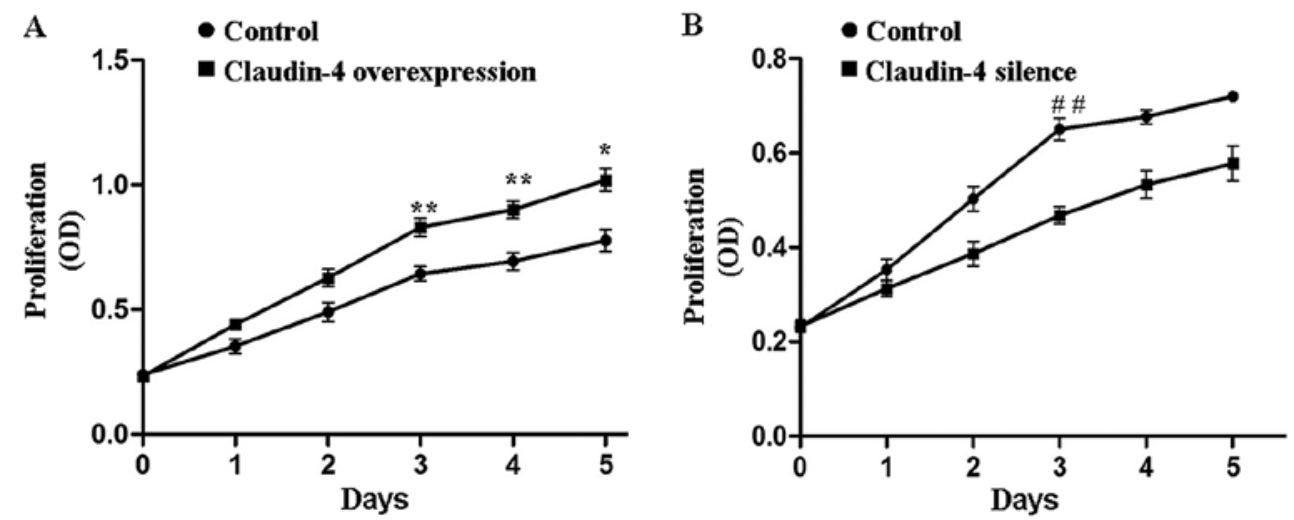

Figure 3. Effects of claudin-4 overexpression and silencing on cell proliferation. (A) Proliferative ability comparison of MCF-7 cells between claudin- 4 overexpression and control groups. The result shows the claudin- 4 overexpression group has a stronger proliferation ability than the control group. Claudin- 4 overexpression, pEGFP-C1-Cldn4 stably transfected MCF-7 cells; control,pEGFP-C1 stably transfected cells. ${ }^{*} \mathrm{P}<0.05$ and ${ }^{* *} \mathrm{P}<0.01$ vs. control. (B) Proliferation of claudin-4-silenced MCF-7 and control cells. Compared to the control group, the proliferation rate of the claudin-4-silenced group was decreased. Claudin-4 silence, PLL3.7-siCldn4 stably transfected MCF-7 cells; control, PLL3.7-scramble stably transfected MCF-7 cells. ${ }^{\text {P }}<0.05$ and ${ }^{\# \#} \mathrm{P}<0.01$ vs. control. Each experiment was carried out in triplicate. The results are presented as the mean $\pm \mathrm{SD}(\mathrm{n}=3)$.
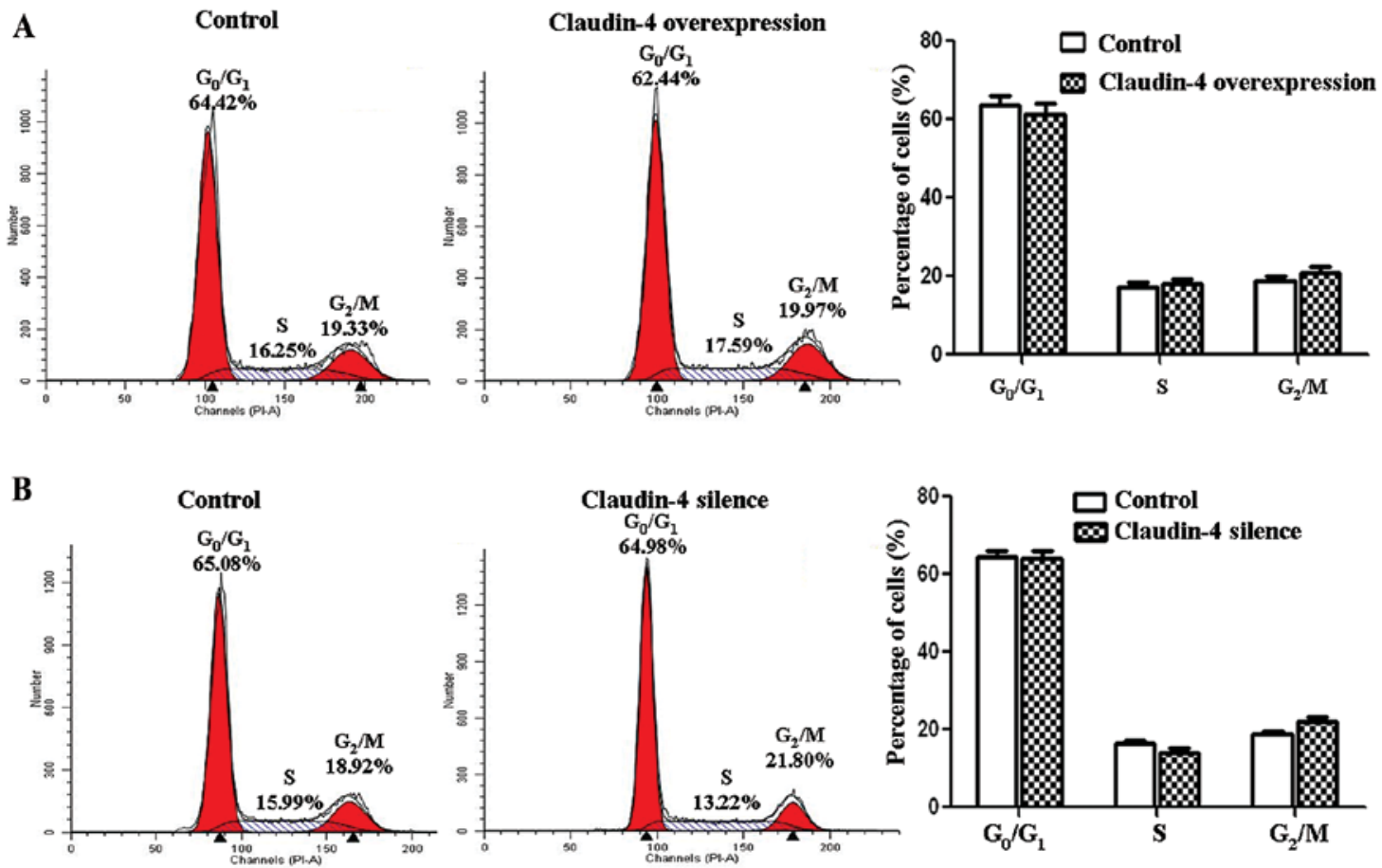

Figure 4. Effects of claudin-4 on the cell cycle progression of MCF-7 cells. Cell cycle analysis of (A) claudin-4 overexpressed MCF-7 cells and (B) claudin-4silenced MCF-7 cells by flow cytometry. The cell-cycle distribution of the profiles was quantified and is shown in bar graphs including G0/G1, S and G2/M phases Claudin-4 had no effect on the cell-cycle progression of MCF-7 cells. Control in (A) pEGFP-C1 stably transfected cells; control in (B) PLL3.7-scramble stably transfected MCF-7 cells.

fluorescence microscope (Leica, Germany) (Fig. 2A). Claudin-4 mRNA and protein levels were downregulated to $(15.95 \pm 1.34)$ and $(32.49 \pm 3.19) \%$ in PLL 3.7-siCldn4 stably transfected MCF-7 cells (claudin-4 silencing) compared to the PLL3.7-scramble-transfected cells (control) $(\mathrm{P}<0.001$ or $\mathrm{P}<0.01$, Fig. 2B and C).

Claudin-4 is involved in MCF-7 cell proliferation. To determine whether claudin- 4 protein influenced the proliferation of breast cancer cell lines, an MTT assay was carried out on the claudin-4-overexpressing MCF-7 cells and the corre- sponding negative control cells. The proliferation capability of claudin- 4 overexpressed MCF-7 cells was significantly stronger (claudin- 4 overexpression vs. control, $\mathrm{P}<0.05$ or $\mathrm{P}<0.01$, Fig. 3A). By contrast, when we knocked down the expression of claudin- 4 in MCF-7 cells, the cell proliferation rate was significantly retarded as compared to the control cells (claudin-4-silence vs. control, $\mathrm{P}<0.05$ or $\mathrm{P}<0.01$, Fig. 3B). The results showed that claudin- 4 significantly enhanced proliferation of the breast cancer cells. However, claudin- 4 did not influence the cell cycle of the breast cancer cells according to our flow cytometric results (Fig. 4). 
A

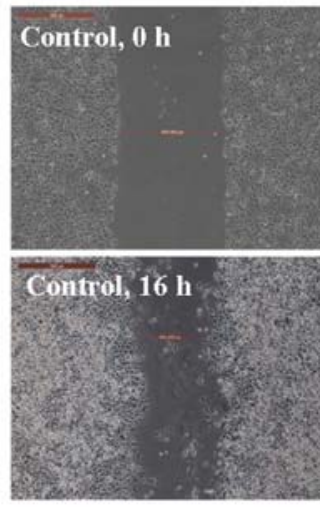

B

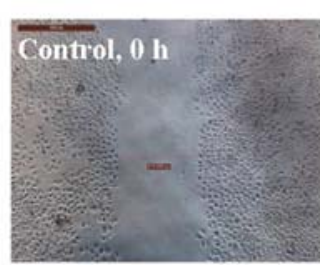

Control, $16 \mathrm{~h}$
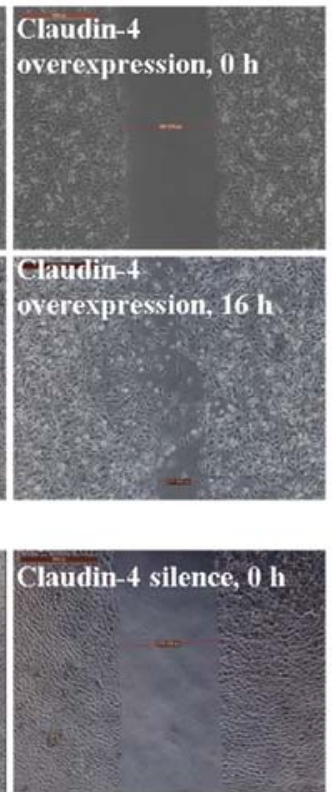

Claudin-4 silence, $16 \mathrm{~h}$
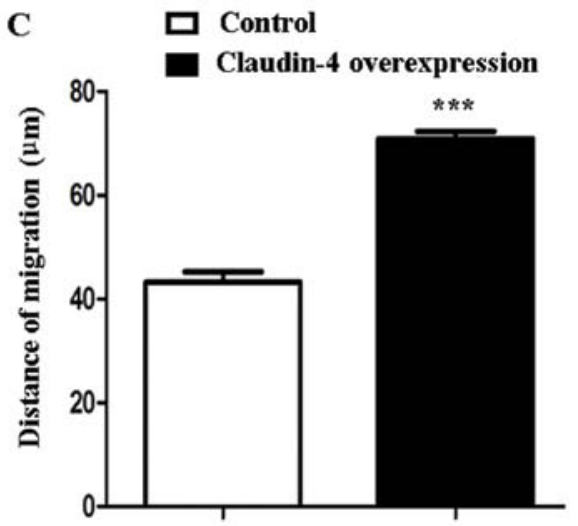

D

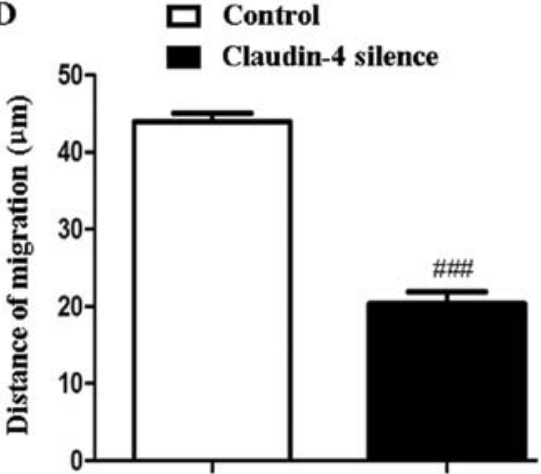

Figure 5. Effects of claudin-4 overexpression and silencing on the migration of MCF-7 cells. (A) Migration of claudin-4 overexpressed MCF-7 cells in a monolayer scrape injury assay. Distances of cell migration were significantly different among the two groups (claudin- 4 overexpression and control). Claudin- 4 overexpressed MCF-7 cells showed stronger migration capability. (B) Scrape injury assay showed claudin-4 silencing inhibited cell migration of cultured MCF-7 cells. Data are shown as the means \pm SD $(n=3)$. (C and D) Quantification results of A and B. Control in (A and C) pEGFP-C1 stably transfected cells; control in (B and D) PLL3.7-scramble stably transfected MCF-7 cells. The results are presented as the mean $\pm \mathrm{SD}(\mathrm{n}=3) .{ }^{* * *} \mathrm{P}<0.001$ vs. control in $\mathrm{C}$, \#\#" $\mathrm{P}<0.001$ vs. control in D.

Claudin-4 regulates MCF-7 cell migration. A scrape injury assay and time-lapse analysis were carried out to assess the effect of claudin- 4 on breast cancer cell migration. The result revealed a significant increase in the average migration distance of claudin-4 overexpression MCF-7 cells compared to the control cells $(70.89 \pm 2.41$ and $43.25 \pm 3.39 \mu \mathrm{m}$, claudin- 4 overexpression vs. control, $\mathrm{P}<0.001$, Fig. $5 \mathrm{~A}$ and $\mathrm{C}$ ). Conversely, the average migration distance of claudin-4 knockdown MCF-7 cells was significantly decreased compared to the control cells (20.35 \pm 2.70 and $43.98 \pm 1.89 \mu \mathrm{m}$, claudin-4 silenced vs. control, $\mathrm{P}<0.001$, Fig. 5B and D).

Claudin-4 affects MCF-7 cell apoptosis. MCF-7 cell apoptosis was assessed using flow cytometry. 5-FU treatment for $24 \mathrm{~h}$ significantly increased the rate of cell apoptosis in claudin-4 overexpressed/silenced cells and corresponding control cells. However, 5-FU-induced apoptosis in claudin-4 overexpressed MCF-7 cells was significantly lower $(6.00 \pm 0.72$ and $16.60 \pm 2.79 \%$, claudin-4 overexpression vs. control, $\mathrm{P}<0.001$, Fig. 6A and C). By contrast, 5-FU-induced apoptosis of MCF-7 cells was increased after claudin-4 knockdown $(34.90 \pm 2.14$ and $18.07 \pm 3.65 \%$, claudin-4 silence vs. control, $\mathrm{P}<0.01$, Fig. 6B and D). These results showed that claudin-4 inhibited apoptosis of breast cancer cells.

Expression of claudin- 4 is regulated by methylation in MCF-7 cells. The methylation status of claudin- 4 was determined in
MCF-7 cells by MSPCR. As shown in Fig. 7A, normal MCF-7 cells exhibited methylated and unmethylated PCR products. Following treatment with 5-AZA, an inhibitor of DNA methylation for $24 \mathrm{~h}$, an unmethylated allele only was identified. 5-AZA treatment induced an increased claudin-4 expression in MCF-7 cells, as demonstrated by RT-PCR and western blotting. After 48 and $72 \mathrm{~h}$ of 5-AZA incubation, the expression of claudin-4 mRNA increased (1.53 \pm 0.36$)$ - and (2.1 \pm 0.33$)$-fold in comparison to the untreated vehicle cells, respectively $(\mathrm{P}<0.05$ or 0.01 , Fig. 7B). Claudin-4 protein expression significantly increased (1.85 \pm 0.48$)-,(2.86 \pm 0.18)$ - and (4.89 \pm 0.44$)$-fold after 24,48 and $72 \mathrm{~h}$ following 5-AZA treatment $(\mathrm{P}<0.05,0.01$ or 0.001, Fig. 7C). This result indicated that the expression of claudin-4 expression was regulated by the methylation status.

Silencing of claudin-4 inhibits the tumor formation of MCF-7 cells in vivo. To explore the role of claudin-4 in in vivo tumor formation, claudin-4-silenced MCF-7 and corresponding control MCF-7 cells $\left(2 \times 10^{6}\right.$ cells) were injected subcutaneously into BALB/c nude mice. Palpable tumors were formed 7 days after injection in control and claudin-4-silenced MCF-7 groups. On day 14, the tumors derived from claudin-4-silenced MCF-7 were significantly smaller than those formed in the control cells $\left(202.2 \pm 82.3\right.$ and $616.7 \pm 177.2 \mathrm{~mm}^{3}$, claudin-4silenced MCF-7 vs. control MCF-7, P<0.01, Fig. 8A-C). The results suggested that knockdown of claudin- 4 inhibited the oncogenicity of MCF-7 cells. 
A
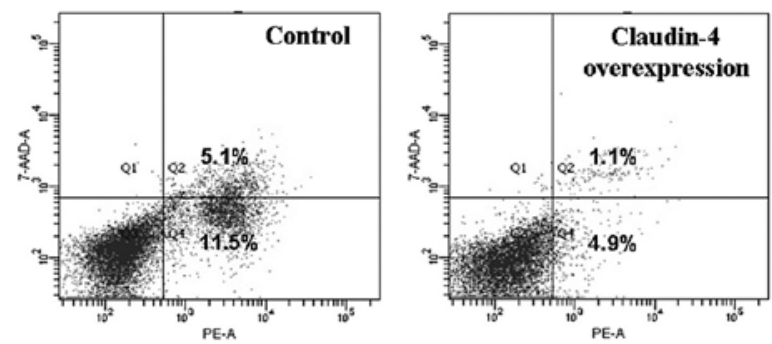

B
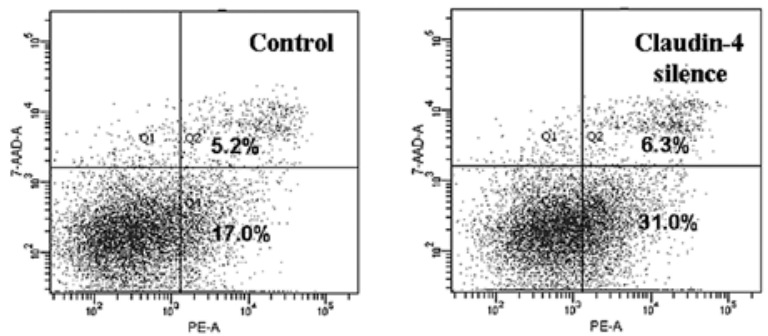

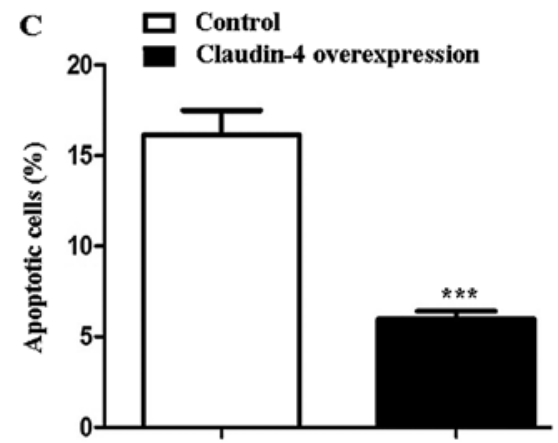

D

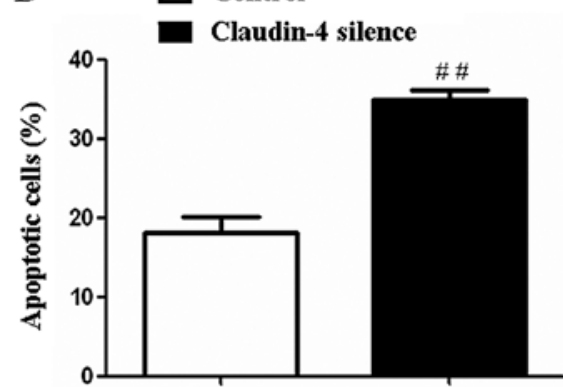

Figure 6. Effects of claudin-4 overexpression and silencing on the apoptosis of MCF-7 cells. (A) Claudin-4 overexpression MCF-7 cells showed lower apoptosis rate than control cells after 5-FU treatment. (B) Apoptosis analysis of control MCF-7 and claudin-4 silenced MCF-7 cells by flow cytometry. The percentages of apoptosis cells in claudin-4 silenced MCF-7 were significantly increased. (C and D) Stand for the quantification results of A and B. Control in (A and C) pEGFP-C1 stably transfected cells; control in (B and D) PLL3.7-scramble stably transfected MCF-7 cells. All the results are presented as mean \pm SD $(\mathrm{n}=3) .{ }^{* * * *} \mathrm{P}<0.001$ vs. control in $\mathrm{C},{ }^{\# \#} \mathrm{P}<0.01$ vs. control in $\mathrm{D}$.

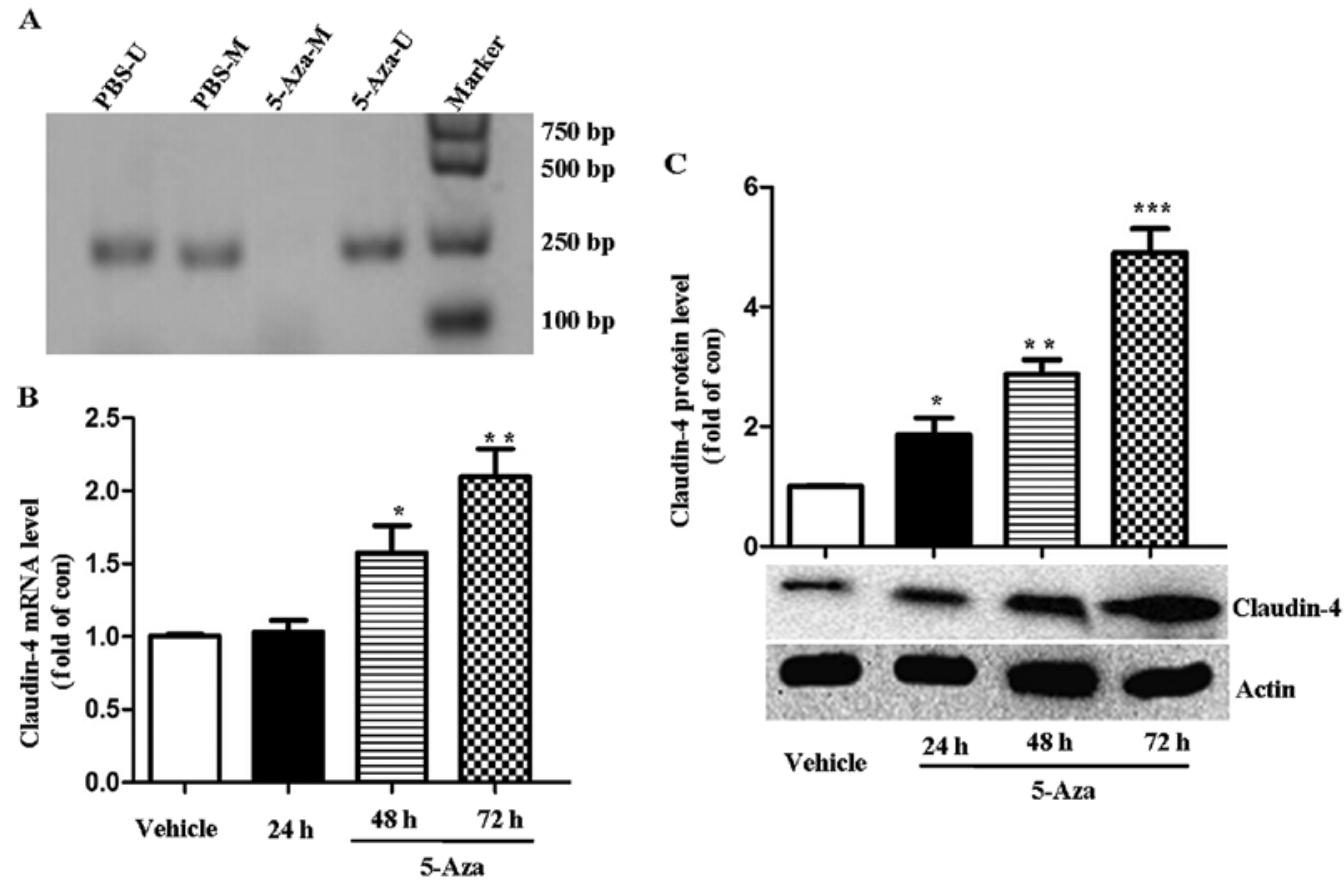

Figure 7. (A) Methylation status affects claudin- 4 expression in MCF-7 cells. MCF-7 exhibited both methylated and unmethylated PCR products. After treated with 5-AZA (10 $\mu \mathrm{mol} / 1)$, an inhibitor of DNA methylation, MCF-7 only exhibited an unmethylated allele. (A) Treatment with 5-AZA resulted in an increased expression of claudin- 4 , as assessed by (B) qRT-PCR and (C) western blotting. All the results are presented as mean \pm SD $(n=3)$. ${ }^{*} \mathrm{P}<0.05,{ }^{* *} \mathrm{P}<0.01$, $^{* * * *} \mathrm{P}<0.001$ vs. vehicle.

\section{Discussion}

Tight junctions exist in the junctional complexes of epithelial and endothelial cells, where they play important roles in various cell activities such as cell adhesion, permeability proliferation and differentiation $(3,4,24)$. Claudins are the major components of tight junctions for backbone and barrier formation (3). The abnormality of claudins has been shown 
A

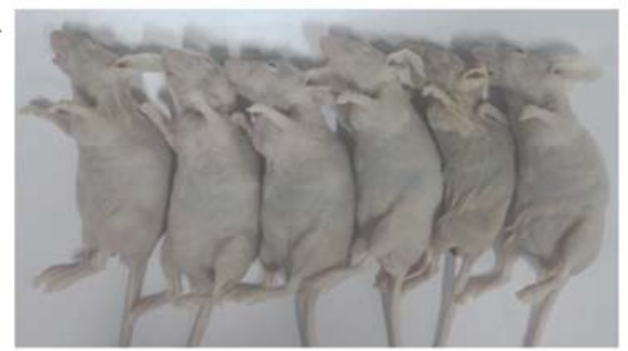

Control MCF-7

B

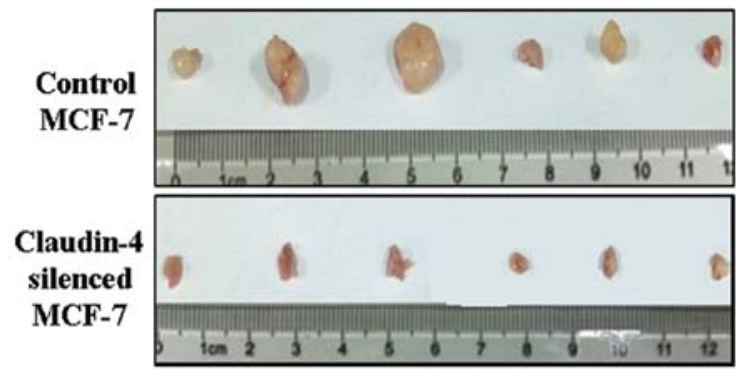

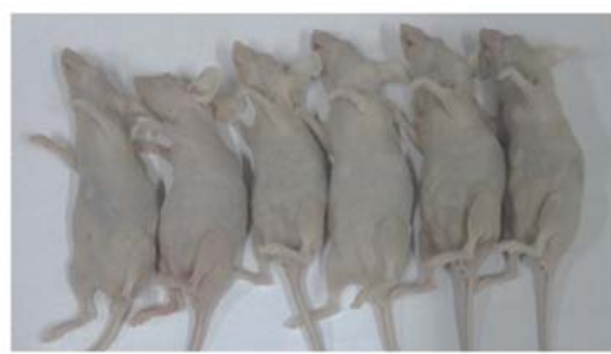

Claudin-4 silenced

MCF-7

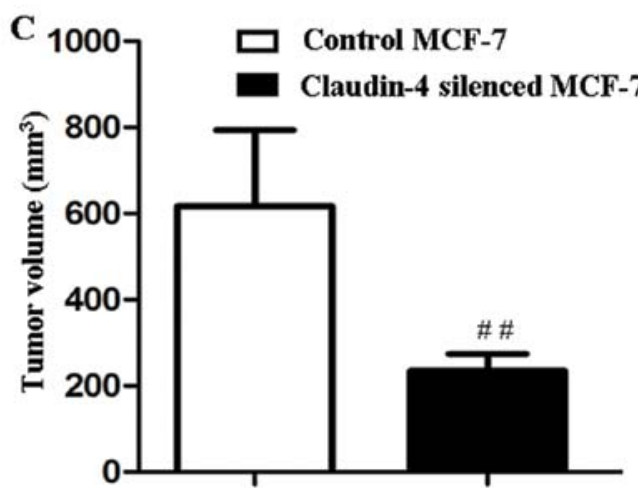

Figure 8. The effect of claudin-4 on the oncogenicity of MCF-7 cells after transplantation into breast fat. (A) Images of the nude mice carrying the tumors in each group (claudin-4-silenced MCF-7, control MCF-7) prior to dissection. (B) Images of tumors formed in each group following dissection. (C) The quantification results of tumor size. The claudin-4-silenced group shows a low oncogenicity compared to the control group. Results are presented as the mean $\pm \mathrm{SD}$ ( $\mathrm{n}=6$ ). ${ }^{\#} \mathrm{P}<0.01$ vs. control.

to contribute to tumor development (25). Previous studies have identified the overexpression of claudin- 4 in breast cancer (18-20), suggesting that claudin-4 be a biomarker for the detection and diagnosis of breast cancer. In the present study, to the best of our knowledge we found for the first time that claudin- 4 promoted the proliferation and migration of breast cancer cells, while inhibiting the apoptosis of these cells in vitro, resulting in a more aggressive phenotype. Claudin-4 inhibition repressed the tumorigenesis of MCF-7 breast cancer cells in nude mice. Moreover, the expression of claudin-4 may be regulated by the methylation status according to our preliminary study.

A high proliferative potential is one of the most important characteristics of malignant tumors (26). Members of the claudin family have been proven to regulate the proliferation of human cancer cells (27). Based on the findings that the expression of claudin- 4 was increased in breast cancer (18-20), we hypothesized that claudin-4 overexpression contributes to the proliferative potential of cancer cells in breast cancer. As expected, we found that cell number expansion was promoted by claudin- 4 in the breast cancer cell lines. The cell-cycle progression of breast cancer cells was not affected by the upregulation or downregulation of claudin-4 expression in the present study. Thus, the precise mechanisms by which claudin- 4 regulates cell expansion should be studied. It has been shown that claudin proteins interact with various proteins through the PDZ domain-binding motif existing in the $\mathrm{COOH}$-terminal of claudins (28). These interactions can serve as adapters for regulatory proteins such as Rab3b and Rab13, and transcription factors such as ZONAB $(29,30)$, regulating cell proliferation.

Apoptosis is another essential factor for maintaining cell/tissue homeostasis. Dysregulation of cell apoptosis is one of the leading mechanisms in tumor formation (31). Recent studies have described the role of claudin proteins in cell apoptosis $(32,33)$. In breast cancer, the anti-apoptotic effect of claudin-1 has been identified (34). In the present study, our results show that claudin-4 may also inhibit the apoptosis of breast cancer cells.

Most malignant tumors exhibit a highly invasive and migratory ability, which is closely associated with tumor metastasis. Previous studies have demonstrated the association between claudin dysregulation and cancer cell metastasis alteration (7). Claudin-4 overexpression has been identified to reduce the invasiveness of pancreatic cancer cells (35). In breast cancer cells, the upregulation of claudin- 6 expression decreases cell invasiveness and migration (22). Claudin-7 downregulation contributes to the increased cellular discohesion and the ability of cancer cells to disseminate (21). Those results indicate that tight junction overexpression decreases cell invasion and motility. However, our results have shown that claudin-4 increased the migration of breast cancer cells. This discrepancy may be that different types of claudins function differently in different cells/tissues due to tissue-specific molecular mechanisms (7). Our finding is consistent with those of a previous study showing that knockdown of claudin-4 in ovarian cancer cell lines results in a decrease in the invasion of these cells, which is associated with increased matrix metalloproteinase-2 activity (36). 
Based on our in vitro studies, claudin-4 overexpression promotes the aggressive behavior of human breast cancer cells, possibly by inhibiting apoptosis and promoting cell proliferation and migration. To confirm our results, we assessed the role of claudin- 4 in tumorigenesis in nude mice. We found that claudin-4 silencing inhibited the tumorigenesis of $\mathrm{MCF}-7$ cells, suggesting that claudin-4 overexpression promotes tumorigenesis in breast cancer. These results are consistent with our in vitro findings, and provides the preclinical evidence for claudin-4 to be a potential candidate for therapeutic target for breast cancer. It has been demonstrated that immunotoxinmediated targeting of claudin- 4 inhibited the proliferation of claudin-4-positive cancers (37).

All of the results suggest that claudin- 4 is important in the development of breast cancer. However, the mechanisms of claudin- 4 regulation in breast cancer remain to be elucidated. Overexpression of claudin-4 may be mediated through multiple mechanisms, one of which is gene epigenetic modification (23). Methylation of 5'-cytosines in $\mathrm{CpG}$ islands is an important epigenetic modulator of gene expression (38). Alterations in the methylation status have been proven to be associated with aberrant gene expression of claudin-4 in pancreatic carcinomas and ovarian cancer $(23,39)$. In the present study, we found that claudin-4 expression was increased in MCF-7 breast cancer cells after unmethylated treatment. The results suggest that the increased expression of claudin-4 was associated with the hypomethylated status in breast cancer. As cultured cells may have an altered methylation pattern compared to their tissue counterparts (21), breast cancer tissue samples have to be examined to confirm our results.

In summary, the present study demonstrates a potential role of claudin- 4 in the pathogenesis of breast cancer via the control of cancer cell proliferation, apoptosis and migration. In addition, our data reveal that methylation controls claudin-4 expression in breast cancer. However, further in-depth investigations on the role and the precise underlying mechanisms of claudin- 4 regulation in breast cancer are necessary.

\section{Acknowledgements}

This study was supported by funding from the Scientific Research Foundation of Guangdong Medical College (no. XB1225), and the Affiliated Hospital of Guangdong Medical College (no. BK201210).

\section{References}

1. Myal Y, Leygue E and Blanchard AA: Claudin 1 in breast tumorigenesis: Revelation of a possible novel 'claudin high' subset of breast cancers. J Biomed Biotechnol 2010: 956897, 2010.

2. Singh AB, Sharma A and Dhawan P: Claudin family of proteins and cancer: An overview. J Oncol 2010: 541957, 2010.

3. Tsukita S, Furuse M and Itoh M: Multifunctional strands in tight junctions. Nat Rev Mol Cell Biol 2: 285-293, 2001.

4. Matter K and Balda MS: Signalling to and from tight junctions. Nat Rev Mol Cell Biol 4: 225-236, 2003.

5. Furuse $M$ and Tsukita S: Claudins in occluding junctions of humans and flies. Trends Cell Biol 16: 181-188, 2006.

6. Van Itallie CM and Anderson JM: Claudins and epithelial paracellular transport. Annu Rev Physiol 68: 403-429, 2006.

7. Morin PJ: Claudin proteins in human cancer: Promising new targets for diagnosis and therapy. Cancer Res 65: 9603-9606, 2005.
8. Soini Y: Expression of claudins 1, 2, 3, 4, 5 and 7 in various types of tumours. Histopathology 46: 551-560, 2005.

9. Sakaguchi T, Suzuki S, Higashi H, Inaba K, Nakamura S, Baba S, Kato T and Konno H: Expression of tight junction protein claudin-5 in tumor vessels and sinusoidal endothelium in patients with hepatocellular carcinoma. J Surg Res 147: 123-131, 2008.

10. Escudero-Esparza A, Jiang WG and Martin TA: The Claudin family and its role in cancer and metastasis. Front Biosci 16: 1069-1083, 2011.

11. Boireau S, Buchert M, Samuel MS, Pannequin J, Ryan JL, Choquet A, Chapuis H, Rebillard X, Avancès C, Ernst M, et al: DNA-methylation-dependent alterations of claudin-4 expression in human bladder carcinoma. Carcinogenesis 28: 246-258, 2007.

12. Liu Y, Sun W, Zhang K, Zheng H, Ma Y, Lin D, Zhang X, Feng L, Lei $\mathrm{W}$, Zhang $\mathrm{Z}$, et al: Identification of genes differentially expressed in human primary lung squamous cell carcinoma. Lung Cancer 56: 307-317, 2007.

13. Paschoud S, Bongiovanni M, Pache JC and Citi S: Claudin-1 and claudin-5 expression patterns differentiate lung squamous cell carcinomas from adenocarcinomas. Mod Pathol 20: 947-954, 2007.

14. Resnick MB, Konkin T, Routhier J, Sabo E and Pricolo VE: Claudin-1 is a strong prognostic indicator in stage II colonic cancer: A tissue microarray study. Mod Pathol 18: 511-518, 2005.

15. Morohashi S, Kusumi T, Sato F, Odagiri H, Chiba H, Yoshihara S, Hakamada K, Sasaki M and Kijima H: Decreased expression of claudin-1 correlates with recurrence status in breast cancer. Int J Mol Med 20: 139-143, 2007.

16. Blanchard AA, Skliris GP, Watson PH, Murphy LC, Penner C, Tomes L, Young TL, Leygue E and Myal Y: Claudins 1, 3, and 4 protein expression in ER negative breast cancer correlates with markers of the basal phenotype. Virchows Arch 454: 647-656, 2009.

17. Osanai M, Murata M, Chiba H, Kojima T and Sawada N: Epigenetic silencing of claudin-6 promotes anchorage-independent growth of breast carcinoma cells. Cancer Sci 98: 1557-1562, 2007.

18. Lanigan F, McKiernan E, Brennan DJ, Hegarty S, Millikan RC, McBryan J, Jirstrom K, Landberg G, Martin F, Duffy MJ, et al: Increased claudin-4 expression is associated with poor prognosis and high tumour grade in breast cancer. Int J Cancer 124: 2088-2097, 2009.

19. Kolokytha P, Yiannou P, Keramopoulos D, Kolokythas A, Nonni A, Patsouris E and Pavlakis K: Claudin-3 and claudin-4: Distinct prognostic significance in triple-negative and luminal breast cancer. Appl Immunohistochem Mol Morphol 22: 125-131, 2014.

20. Szasz AM, Nemeth Z, Gyorffy B, Micsinai M, Krenacs T, Baranyai Z, Harsanyi L, Kiss A, Schaff Z, Tokes AM, et al: Identification of a claudin-4 and E-cadherin score to predict prognosis in breast cancer. Cancer Sci 102: 2248-2254, 2011.

21. Kominsky SL, Argani P, Korz D, Evron E, Raman V, Garrett E, Rein A, Sauter G, Kallioniemi OP and Sukumar S: Loss of the tight junction protein claudin-7 correlates with histological grade in both ductal carcinoma in situ and invasive ductal carcinoma of the breast. Oncogene 22: 2021-2033, 2003.

22. Wu Q, Liu Y, Ren Y, Xu X, Yu L, Li Y and Quan C: Tight junction protein, claudin-6, downregulates the malignant phenotype of breast carcinoma. Eur J Cancer Prev 19: 186-194, 2010.

23. Litkouhi B, Kwong J, Lo CM, Smedley JG III, McClane BA, Aponte M, Gao Z, Sarno JL, Hinners J, Welch WR, et al: Claudin-4 overexpression in epithelial ovarian cancer is associated with hypomethylation and is a potential target for modulation of tight junction barrier function using a C-terminal fragment of Clostridium perfringens enterotoxin. Neoplasia 9: 304-314, 2007.

24. Abuazza G, Becker A, Williams SS, Chakravarty S, Truong HT, Lin F and Baum M: Claudins 6, 9, and 13 are developmentally expressed renal tight junction proteins. Am J Physiol Renal Physiol 291: F1132-F1141, 2006.

25. Oliveira SS and Morgado-Díaz JA: Claudins: Multifunctional players in epithelial tight junctions and their role in cancer. Cell Mol Life Sci 64: 17-28, 2007.

26. Lazarevich NL and Fleishman DI: Tissue-specific transcription factors in progression of epithelial tumors. Biochemistry 73: 573-591, 2008. 
27. Zavala-Zendejas VE, Torres-Martinez AC, Salas-Morales B, Fortoul TI, Montaño LF and Rendon-Huerta EP: Claudin-6, 7, or 9 overexpression in the human gastric adenocarcinoma cell line AGS increases its invasiveness, migration, and proliferation rate. Cancer Invest 29: 1-11, 2011.

28. Itoh M, Furuse M, Morita K, Kubota K, Saitou M and Tsukita S: Direct binding of three tight junction-associated MAGUKs, $\mathrm{ZO}-1, \mathrm{ZO}-2$, and $\mathrm{ZO}-3$, with the $\mathrm{COOH}$ termini of claudins. J Cell Biol 147: 1351-1363, 1999.

29. Balda MS, Garrett MD and Matter K: The ZO-1-associated Y-box factor ZONAB regulates epithelial cell proliferation and cell density. J Cell Biol 160: 423-432, 2003.

30. Yamamoto Y, Nishimura N, Morimoto S, Kitamura H, Manabe S, Kanayama HO, Kagawa S and Sasaki T: Distinct roles of Rab3B and Rab13 in the polarized transport of apical, basolateral, and tight junctional membrane proteins to the plasma membrane. Biochem Biophys Res Commun 308: 270-275, 2003.

31. Evan GI and Vousden KH: Proliferation, cell cycle and apoptosis in cancer. Nature 411: 342-348, 2001.

32. Guo Y, Xu X, Liu Z, Zhang T, Zhang X, Wang L, Wang M, Liu Y, Lu Y, Liu Y, et al: Apoptosis signal-regulating kinase 1 is associated with the effect of claudin-6 in breast cancer. Diagn Pathol 7 : $111,2012$.

33. Armstrong SM, Wang C, Tigdi J, Si X, Dumpit C, Charles S, Gamage A, Moraes TJ and Lee WL: Influenza infects lung microvascular endothelium leading to microvascular leak: Role of apoptosis and claudin-5. PLoS One 7: e47323, 2012.
34. Akasaka H, Sato F, Morohashi S, Wu Y, Liu Y, Kondo J, Odagiri H, Hakamada $\mathrm{K}$ and Kijima H: Anti-apoptotic effect of claudin-1 in tamoxifen-treated human breast cancer MCF-7 cells. BMC Cancer 10: 548, 2010.

35. Michl P, Barth C, Buchholz M, Lerch MM, Rolke M, Holzmann KH, Menke A, Fensterer H, Giehl K, Löhr M, et al: Claudin-4 expression decreases invasiveness and metastatic potential of pancreatic cancer. Cancer Res 63: 6265-6271, 2003.

36. Agarwal R, D'Souza T and Morin PJ: Claudin-3 and claudin-4 expression in ovarian epithelial cells enhances invasion and is associated with increased matrix metalloproteinase-2 activity. Cancer Res 65: 7378-7385, 2005.

37. Hashimi SM, Yu S, Alqurashi N, Ipe DS and Wei MQ: Immunotoxin-mediated targeting of claudin- 4 inhibits the proliferation of cancer cells. Int J Oncol 42: 1911-1918, 2013.

38. Esteller M: Relevance of DNA methylation in the management of cancer. Lancet Oncol 4: 351-358, 2003.

39. Sato N, Maitra A, Fukushima N, van Heek NT, Matsubayashi H, Iacobuzio-Donahue CA, Rosty C and Goggins M: Frequent hypomethylation of multiple genes overexpressed in pancreatic ductal adenocarcinoma. Cancer Res 63: 4158-4166, 2003. 